\title{
The hybrid method for the plate-finned tube evaporator design process
}

\author{
Giuseppe Starace $^{1^{*}}$, Silvia Macchitella ${ }^{2}$, and Gianpiero Colangelo ${ }^{2}$ \\ ${ }^{1}$ LUM University, Department of Management, Finance and Technology, 70010 Casamassima (BA), \\ Italy \\ ${ }^{2}$ University of Salento, Department of Engineering for Innovation, 73100 Lecce, Italy
}

\begin{abstract}
The plate-finned tube evaporator performance, in terms of heat transfer rate and refrigerant pressure drops, is influenced by several choices done during the design process to be carried out complying with different constraints. In this paper different refrigerant circuitry layout options together with other parameters variations were investigated with the purpose of supporting designers. Performance predictions were calculated using the hybrid method as well as appropriate Performance Evaluation Criteria (PEC) were adopted to select the best layout. The hybrid method has been here revised and improved aiming at modelling heat exchangers with an approach closer to real configurations that include complex circuit layouts. The method was chosen as its main advantage (high accuracy in the results with low computational costs) allowed to easily perform operating conditions modifications to be compared.
\end{abstract}

\section{Introduction}

Good design and optimization processes are of great importance for heat exchangers in order to reduce either production or operating costs. The design process itself should be lean and accurate at the same time: often heat exchangers are oversized due to poor accuracy in design process leading to higher production costs, while, on the other hand, greater precision achieved with CFD approaches can severely slow down the optimization process and still produce high design costs.

In order to save computational efforts, while getting high accuracy of the results, Starace et al. [1] developed a powerful alternative design procedure, the hybrid method, using a multiscale approach starting from data sets coming from either numerical, analytical correlations or from experimental investigations.

The hybrid method was successful implemented on compact cross-flow heat exchangers using the results of CFD simulations performed by Carluccio et al. [2] on both the finned surfaces of the HXs. Then, it was adapted to countercurrent evaporative condensers using data coming from small-scale experimental investigations [3]. Results show how the method is effective in predicting the outlet temperature and humidity with a deviation of $2.5 \%$ and $4 \%$ respectively compared to experimental data. The same method is also suitable

*Corresponding author: starace@lum.it 
for calculating the performance of plate-finned evaporators with simple refrigerant circuit layout [4]. Other approaches using finite element discretization have been developed for the design of fin and tube exchangers such as that one proposed by Corberan et al. [5] applied on finned tube evaporators and condensers, considering also the air dehumidification process. Tarrad and Al-Nadawi [6] developed a small-scale numerical model to calculate the performance of finned tube evaporators, working with pure and zeotropic refrigerants, showing a good matching of calculated to experimental data. Empirical correlations are, instead, used to evaluate the heat transfer coefficients, the pressure drops and the flow regimes inside the tubes of a fin and tube evaporator through the model proposed by Tong et al. [7]. A finite volume approach was also used by Joppolo et al. [8] to study the influence of circuit layout on a fin and tube condenser performance through the $\varepsilon$-NTU method. Genetic algorithm or simulation tools for the optimization of the refrigerant circuitry have been developed considering the maximum heat exchanger capacity $[9,10]$, the minimum heat transfer surface under the same heat transfer rate [10] or the minimum entropy production [11], without evaluating refrigerant pressure drop and so operating costs during the optimization process. According to studies conducted by Yun and Lee [12] and Matos et al. [13], the best way to reduce costs and optimize the geometry of a heat exchanger is to modify the circuitry layout with respect to changing other geometrical parameters such as the fin and the tube geometry or the overall dimensions which are often conditioned by installation or production constraints.

In the present work, a new feature has been added to the hybrid method algorithm, chosen for its characteristic of combining accuracy and low computational costs, in order to be applied also to evaporative exchangers with complex circuit arrangement. The method uses a discretization procedure of the HX whole geometry and for every elementary volume performs a routine on both refrigerant and air side in order to obtain heat transfer parameters through a regression technique.

Several Performance Evaluation Criteria (PEC) have been developed in order to evaluate the performance of heat exchangers: they can be categorized as criteria based on the first law of thermodynamics [14] and criteria based on the second law of thermodynamics [15]. Furthermore, criteria used for heat exchangers operating with single-phase fluids are not suitable for application in two-phase heat exchangers [16]. In this work, a trade-off analysis has been performed to compare different refrigerant circuitry arrangements, considering two-phase fluid's effects.

\section{The hybrid method}

The evaporator considered in this case study is a staggered finned tubes exchanger, working with a refrigerant that evaporates due to the heat exchange with the air flowing between the fins in the normal direction to the tubes. The refrigerant flow is divided into two or more complex circuits, consisting of the same number of pipes. The curves that join the pipes are neglected from the heat transfer process and, therefore, considered adiabatic.

The model uses a three-dimensional matrix to identify each of the tube-centered elementary cells which the entire geometry of the HX is divided into (Fig. 1). As the evaporator is arranged in staggered pipes, at the bottom of the odd rows and at the top of each even row is placed an edge cell that does not host any pipe. The calculation of the parameters in the border cells is treated separately. For all the other cells the heat transfer rate, as well as the wall temperature, is calculated through an iterative procedure that needs the following input data:

- the HX geometry;

- the refrigerant circuit layout;

- the operating conditions; 
- the regression coefficients, obtained by applying the results of experimental, numerical or analytical studies.

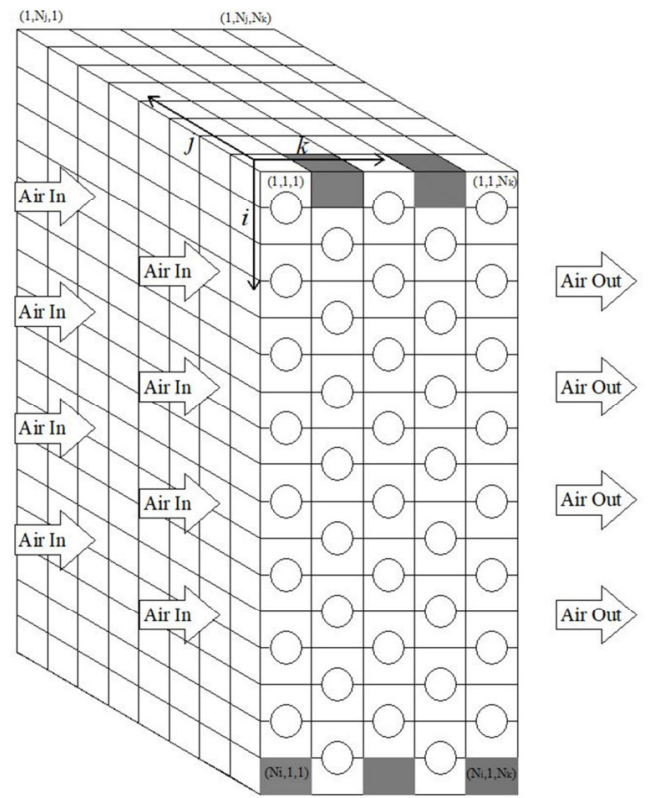

Fig. 1: Discretization in channels, tube sections and rows.

Once these data have been declared, the algorithm identifies, for each cell, the refrigerant flow direction, the circuit which the tube belongs to and also the branch tube (Fig. 2 (a)), i.e. the previous tube in the flow order of the refrigerant, in order to assign to each cell the refrigerant flow rate and the vapor quality corresponding to the considered circuit. In the first delivery cell of each circuit, the flow rate and the vapor quality are set equal to the input parameters; for all the other cells the algorithm assigns the same characteristics of the refrigerant at the outlet of the branch pipe, assuming that curve pipe sections are adiabatic. Air flow through the first row of the HX is considered uniformly distributed, while the distribution in each of the following rows is obtained as a mixture of the air coming from the cells of the previous rows (Fig. 2 (b)). Air streams in other directions, apart from that one normal to the plane containing pipes, are considered negligible.

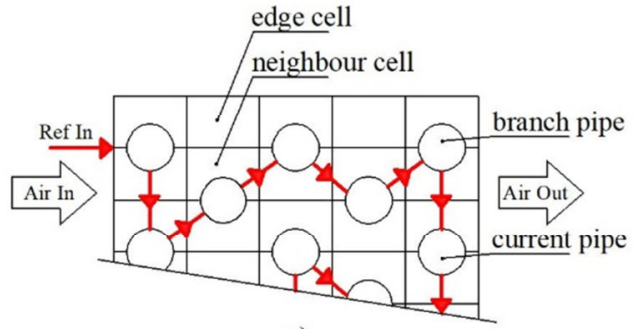

a)

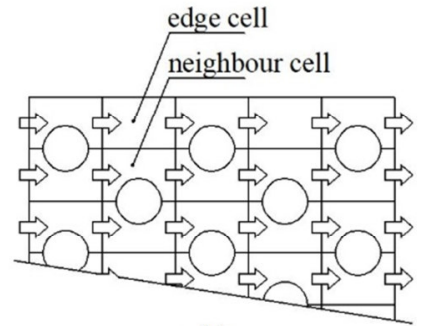

b)

Fig. 2: Representation of cells and pipes (a) and air path (b).

For each cell of the HX, the algorithm iteratively calculates the wall temperature of the pipe as long as the convergence condition between the heat transfer rate on the air side and that 
on the refrigerant side is verified, considering the convective contribution of the air and refrigerant and conductive contribution of the piping:

$$
\dot{\boldsymbol{Q}}_{R}=\dot{\boldsymbol{Q}}_{\boldsymbol{A}}
$$

The other thermodynamic variables are then obtained through correlations in Table 1 as a function of the inner and outer wall temperature.

Table 1: Correlations for refrigerant side and air side variables.

\begin{tabular}{lc|lc} 
Refrigerant side & Reference & Air side & Reference \\
\hline Total heat transfer & {$[17,18]$} & Lewis number & {$[20]$} \\
Pressure drop & {$[19]$} & Heat transfer coefficient & {$[21]$} \\
& & Overall fin efficiency & {$[22]$} \\
& Pressure drop & {$[23]$} \\
& Friction factor & {$[24]$} \\
& & Air specific humidity & {$[25]$} \\
\hline
\end{tabular}

The heat transfer rates of the edge cells are not obtained through the convergence routine, but they are calculated as $10 \%$ of the heat transfer rates of the neighbour cells, which are located below the edge cell in odd ranks and above in even ranks (Fig. 2 (a)). On the other hand, the neighbour cells are expected to have a higher heat exchange than the others under the same conditions, due to a bigger exchange surface, as the edge cell does not contain any pipe.

Once the calculation has been completed on all the cells, the algorithm checks pressure drops on the air-side and refrigerant-side. The pressure drop at air side is calculated as:

$$
\Delta p_{A}(i, j)=\sum_{k=1}^{N_{k}} \Delta p_{A}(i, j, k)
$$

Then, if the condition in Eq. (3) is not satisfied, the algorithm distributes the air mass flow rate once again in each cell, adjusting the flow rate proportionally to the deviation from the mean value.

$$
\begin{gathered}
\Delta \boldsymbol{p}_{A}(\boldsymbol{i}, \boldsymbol{j})=\Delta \boldsymbol{p}_{A, \boldsymbol{m}} \\
\Delta \boldsymbol{p}_{\boldsymbol{R}, \mathrm{z}}=\Delta \boldsymbol{p}_{\boldsymbol{R}, \boldsymbol{m}}
\end{gathered}
$$

The pressure drops for each refrigerant circuit should be equal to the mean value, with a tolerance of $1 \%$, as in Eq. (4). Then, the algorithm distributes the refrigerant flow rates among the circuits until the condition (4) is verified for each $z$-th circuit. The air and refrigerant flow rate are modified in accordance with the principle of conservation of the total input mass flow rate.

Frost formation on tube surface is not yet modelled.

\subsection{Regression analysis}

A quadratic regression analysis aims to determine the relationship between the input and output variables on both the air and the refrigerant sides. In this case, the data used to perform the regression technique were calculated from the experimental correlations showed in Table 1, but the high flexibility of the model allows to use both the results of experimental tests or numerical analysis, when available. Refrigerant side response variable $x_{R \text {,out }}$ is calculated as in Eq. (5), while air side response variables $T_{A, \text { out }}, i_{A, \text { out }}, \Delta p_{A, \text { out }}$ are obtained through Eq. (6). 


$$
\begin{aligned}
& \beta \cdot \alpha^{T} \\
& \beta \cdot \gamma^{T}
\end{aligned}
$$

where $\boldsymbol{\beta}$ is the vector containing the 15 polynomial coefficients obtained through the regression analysis, while $\boldsymbol{\alpha}$ and $\boldsymbol{\gamma}$ are the vectors whose elements are showed in Table 2 and Table 3 respectively.

Table 2: Elements of vector $\alpha$.

\begin{tabular}{cccccc} 
Element & Value & Element & Value & Element & Value \\
\hline$\alpha_{0}$ & 1 & $\alpha_{5}$ & $G_{R} x_{R, i n}$ & $\alpha_{11}$ & $T_{R} T_{w, i}$ \\
$\alpha_{1}$ & $G_{R}$ & $\alpha_{6}$ & $G_{R} T_{w, i}$ & $\alpha_{12}$ & $G_{R}^{2}$ \\
$\alpha_{2}$ & $x_{R, i n}$ & $\alpha_{7}$ & $G_{R} T_{R}$ & $\alpha_{13}$ & $x_{R, i n}^{2}$ \\
$\alpha_{3}$ & $T_{w, i}$ & $\alpha_{8}$ & $x_{R, i n} T_{w, i}$ & $\alpha_{14}$ & $T_{w, i}^{2}$ \\
$\alpha_{4}$ & $T_{R}$ & $\alpha_{9}$ & $x_{R, i n} T_{R}$ & $\alpha_{15}$ & $T_{R}^{2}$ \\
\hline
\end{tabular}

Table 3: Elements of vector $\gamma$.

\begin{tabular}{cccccc} 
Element & Value & Element & Value & Element & Value \\
\hline$\gamma_{0}$ & 1 & $\gamma_{5}$ & $T_{A, i n} R H_{A, i n}$ & $\gamma_{11}$ & $V_{A, i n} T_{w, o}$ \\
$\gamma_{1}$ & $T_{A, i n}$ & $\gamma_{6}$ & $T_{A, i n} V_{A, i n}$ & $\gamma_{12}$ & $T_{A, i n}^{2}$ \\
$\gamma_{2}$ & $R H_{A, i n}$ & $\gamma_{7}$ & $T_{A, i n} T_{w, o}$ & $\gamma_{13}$ & $R H_{A, \text { in }}^{2}$ \\
$\gamma_{3}$ & $V_{A, i n}$ & $\gamma_{8}$ & $R H_{A, i n} V_{A, i n}$ & $\gamma_{14}$ & $V_{A, i n}^{2}$ \\
$\gamma_{4}$ & $T_{w, o}$ & $\gamma_{9}$ & $R H_{A, i n} T_{w, o}$ & $\gamma_{15}$ & $T_{w, o}^{2}$ \\
\hline
\end{tabular}

\section{Circuitry layout}

When designing an evaporator, the optimization process is very complex, due to the high number of design variables. For example, when high flow rates are necessary, splitting the refrigerant flow across two or more circuits is the way to reduce refrigerant pressure drops. In this work, four different tests, with three different sets of circuitry configurations, have been run in order to investigate the influence of circuit layout on HX performance in terms of heat transfer rate and refrigerant pressure drops. Set 1, shown in Fig. 3, has four layouts: the circuit entrances are placed all on the same side of the heat exchanger as well as the outlet pipes, which were located on the opposite side. The air flowed across the fins, normal to the axes of the pipes and the air inlet is placed on the same side of refrigerant entrances. In Set 2 (Fig. 4), instead, the air inlet is located on the same side of refrigerant outlets. Set 3 (Fig. 5) is composed by three configurations, all made by 4-circuits layouts with a greater number of pipes per row (12 tubes per row in Set 3, 8 tubes per row in Set 1 and Set 2).

Each test had a specific goal, as expressed below:

- $\quad$ Test $a$ : investigation on circuitry layouts Set 1 with different refrigerants;

- Test $b$ : investigation on circuitry layouts Set 1 with different refrigerant flow rates, but same heat transfer rate;

- $\quad$ Test $c$ : investigation on circuitry layouts Set 2 compared with Set 1;

- $\quad$ Test $d$ : investigation on circuitry layouts Set 3 composed all by 4-circuits layouts in order to help designers to optimize evaporator circuit arrangement. 


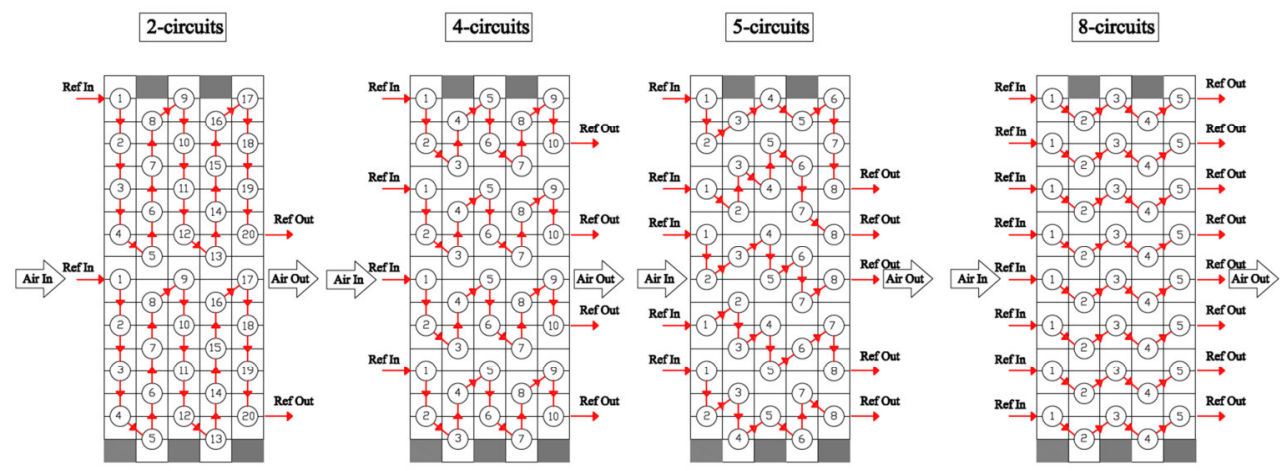

Fig. 3: Circuitry layouts Set 1.
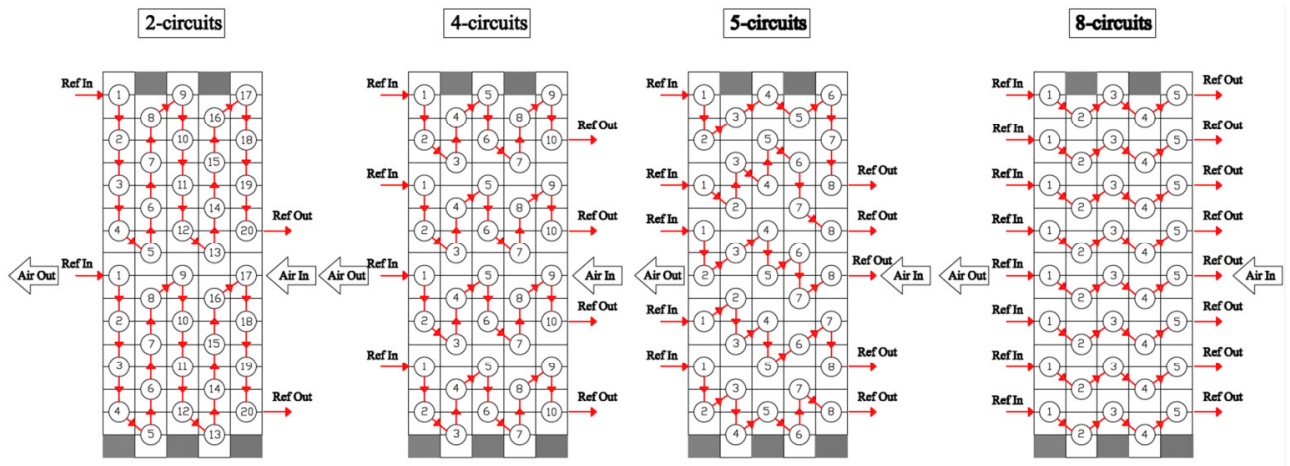

Fig. 4: Circuitry layouts Set 2.

a)

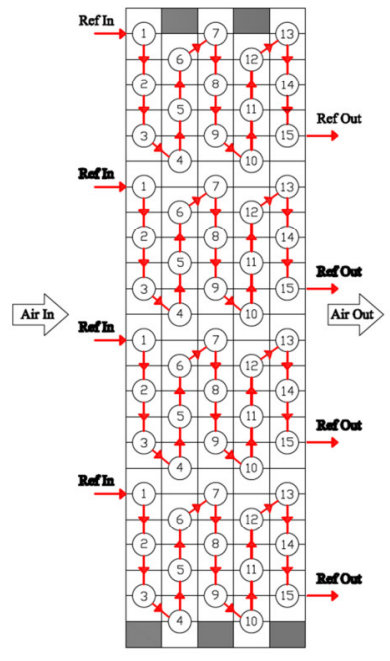

b)

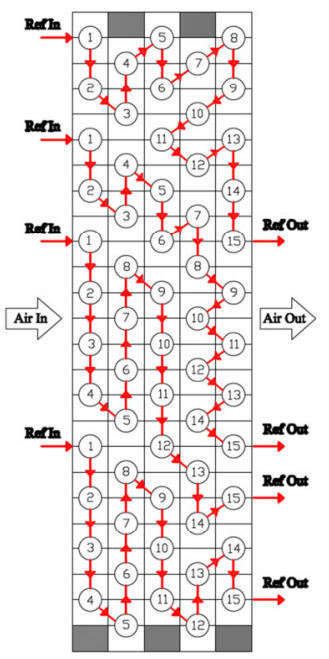

c)

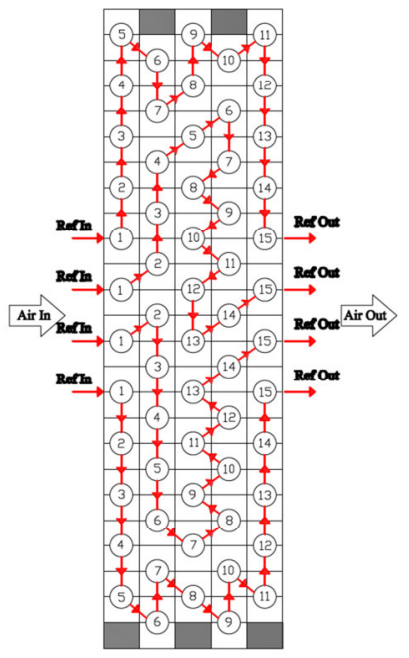

Fig. 5: Circuitry layouts Set 3. 


\section{Results and discussion}

Results of hybrid method implementation on a 5-rows evaporator, with different circuit configurations, are here discussed in terms of heat transfer rate, refrigerant pressure drops and compared through a Performance Evaluation Criteria. As shown in Table 4, four tests have been carried out on three different sets of configurations, with the aim to help designers to make design choices, by varying the refrigerant fluid (test $a$ ), the refrigerant mass flow rate at same heat transfer rate $($ test $b)$, the air inlet side (test $c)$ and the number of tubes per row (test $d$ ). Geometrical parameters of tested coil are summarized in Table 5.

Table 4: Air and refrigerant inlet conditions for test $a$, test $b$, test $c$ and test $d$.

\begin{tabular}{|c|c|c|c|c|c|}
\hline Quantity & Unit & Test a & Test b & Test c & Test d \\
\hline Refrigerant fluid & - & $\begin{array}{c}\text { a) R134a/R410a/R32 } \\
\text { b) R404a/R507a/ } \\
\text { R1234yf/R1234ze }\end{array}$ & R134a & R32 & $\mathrm{R} 32$ \\
\hline Number of tubes per row & - & 8 & 8 & 8 & 12 \\
\hline Refrigerant mass flow rate & $\mathrm{kg} / \mathrm{s}$ & $\begin{array}{l}\text { a) } 0.047 \\
\text { b) } 0.058\end{array}$ & $\begin{array}{c}0.047 / 0.103 / \\
0.122 / 0.195\end{array}$ & 0.036 & 0.047 \\
\hline Air mass flow rate & $\mathrm{kg} / \mathrm{s}$ & $\begin{array}{l}\text { a) } 0.644 \\
\text { b) } 0.515\end{array}$ & 0.644 & 0.644 & 0.940 \\
\hline Evaporation temperature & $\mathrm{K}$ & 271.5 & 271.5 & 271.5 & 271.5 \\
\hline Air inlet temperature & $\mathrm{K}$ & 288 & 288 & 288 & 288 \\
\hline Air inlet relative humidity & - & 0.65 & 0.65 & 0.65 & 0.65 \\
\hline Inlet vapor quality & - & 0.2 & 0.2 & 0.2 & 0.2 \\
\hline Air inlet velocity & $\mathrm{m} / \mathrm{s}$ & $\begin{array}{l}\text { a) } 5 \\
\text { b) } 4\end{array}$ & 5 & 5 & 5 \\
\hline
\end{tabular}

Table 5: Geometrical parameters of tested coil.

\begin{tabular}{lcclcc}
\hline \multicolumn{2}{c}{ Tubes } & & & \multicolumn{2}{c}{ Fins } \\
\hline Quantity & Unit & Value & Quantity & Unit & Value \\
\hline Material & - & Copper & Material & - & Alluminium \\
Internal diameter & $\mathrm{mm}$ & 7.38 & Thickness & $\mathrm{mm}$ & 0.1 \\
External diameter & $\mathrm{mm}$ & 7.94 & Pitch & $\mathrm{mm}$ & 2 \\
Length & $\mathrm{mm}$ & 500 & & & \\
Longitudinal pitch & $\mathrm{mm}$ & 21.65 & & & \\
Transversal pitch & $\mathrm{mm}$ & 25 & & & \\
\hline
\end{tabular}

In test $a$ the goal was to investigate different performance, while changing the number of circuits. Variations of heat transfer rate and refrigerant pressure drop as a function of number of circuits are shown in Fig. 6 for case a) with refrigerant R134a, R410a and R32 and in Fig. 7 for case b) with refrigerant R404a, R507a, R1234yf and R1234ze. Test a was carried out on circuitry layouts Set 1, as shown in Fig. 3.

Results showed that heat transfer rate decreases almost linearly when the considered number of circuits increases. A heat transfer rate mean reduction for the 8-circuits configuration of $11.14 \%$, for case a) and of $12.12 \%$ for case b) with respect to 2-circuits configuration can be observed for all the refrigerant considered. Increasing the number of circuits leads to a reduction in the refrigerant flow rate passing through each circuit and, therefore, to a reduction of the convective heat transfer coefficient which, consequently, has a negative effect on the global heat transfer. As a consequence, the vapor quality at the outlet of the 8-circuits configuration was found lower than the 2-circuits one. On the other hand, for all the considered refrigerants, pressure drops strongly decrease with a parabolic trend as the number of circuits increase, due to flow rate reduction through each circuit. 

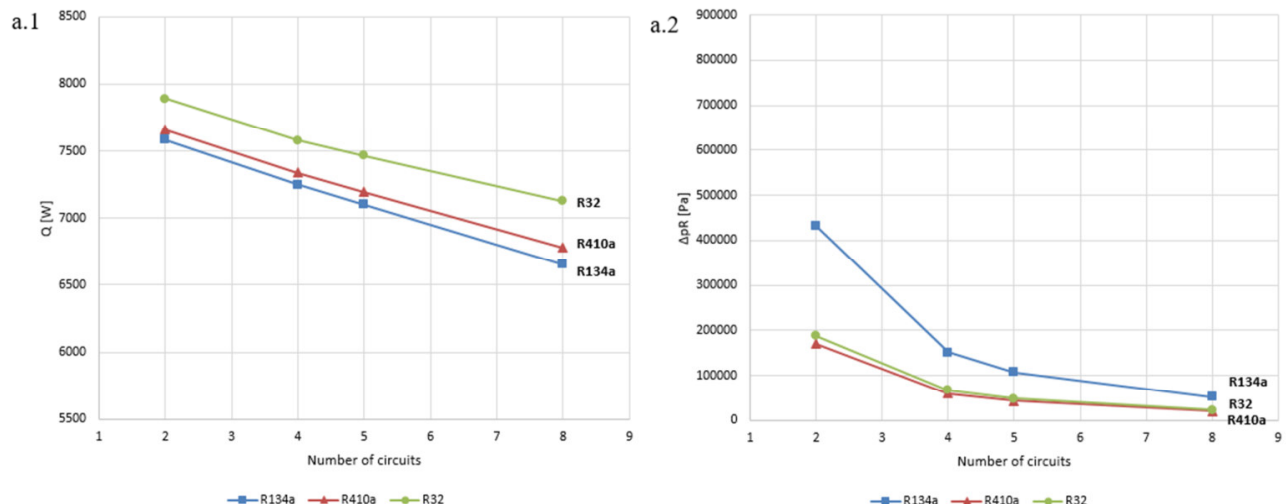

Fig. 6: Test a, case a) : heat transfer rate (a.1) and refrigerant pressure drops (a.2) for each circuit layout of Set 1 for refrigerants R134a, R410a, R32.
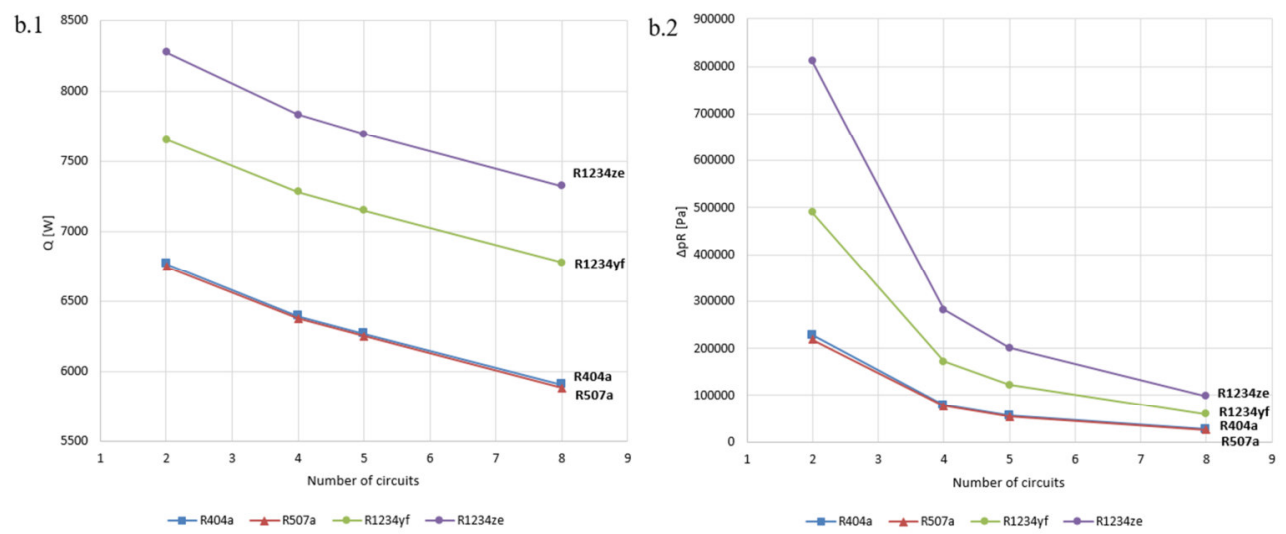

Fig. 7: Test a, case b) : heat transfer rate (b.1) and refrigerant pressure drops (b.2) for each circuit layout of Set 1 for refrigerant R404a, R507a, R1234yf and R1234ze.

a

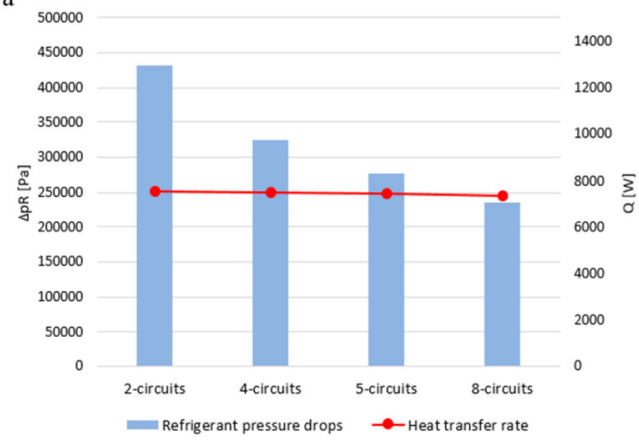

b

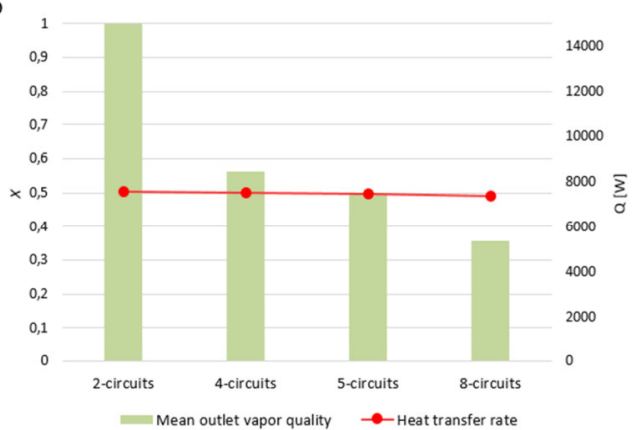

Fig. 8: Test $b$ : Refrigerant pressure drops (a) and mean outlet vapor quality (b) for each circuit layout of Set 1. 
a

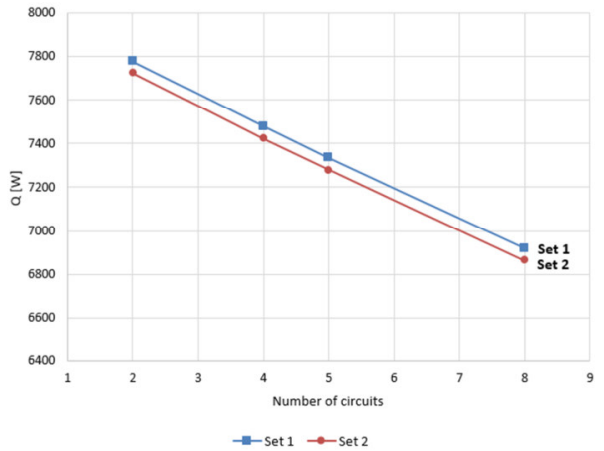

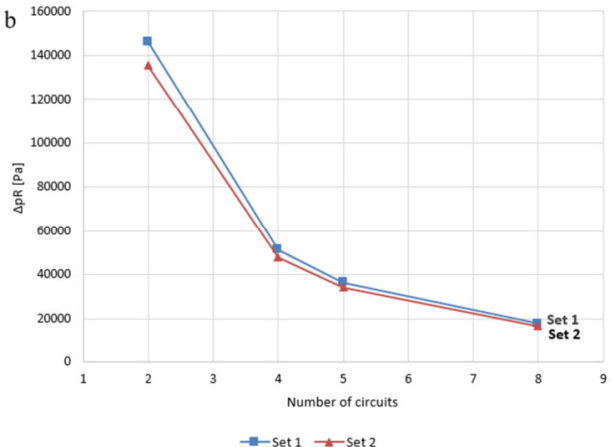

Fig. 9: Test $c$ : Heat transfer rate (a) and refrigerant pressure drops (b) for each circuit layout of Set 1 in comparison with Set 2.

Among the refrigerants of case $a, \mathrm{R} 32$ seems to be the most performing one as it has the highest heat transfer rate with almost the lowest pressure drops. The same cannot be said for R1234ze which has the highest heat transfer rate among case b) refrigerants, but it shows also the highest pressure drops. On the other hand, R134a shows the worst performance with lowest heat transfer rate and highest pressure drops.

Test $b$ was carried out with refrigerant R134a on Set 1 circuitry configuration (Fig. 3), with the aim to compare different layouts at same heat transfer rate in terms of refrigerant pressure drops and outlet vapor quality, by varying refrigerant mass flow rate at inlet, as shown in Table 4.

Results in Fig. 8 show that the 8-circuits configuration has a lower refrigerant pressure drops at same heat transfer rate, with respect to 2-circuits layout. As a consequence, a coil designer could choose a 8-circuits configuration in order to reduce operating costs, by increasing the refrigerant flow rate and maintaining the same performance in terms of heat transfer rate. In test $b$ it is shown how it's possible to decrease pressure drops of $45.3 \%$ by increasing the refrigerant mass flow rate of $314 \%$, at same performance level only adopting a 8-circuit configuration instead of 2-circuits one.

Choosing a layout with a high number of circuits, then, leads to another consequence: if a given heat transfer rate has to be reached, the total flow rate has to be increased, due to the lower local velocities and the decreased mean outlet vapor quality (in Fig. 8 (b), the vapor quality goes from 0.99 in the 2-circuits configuration to a value of 0.35 in the 8 -circuits layout (-64\%). Here the principle of the flooded evaporator can be recognized, that implies the recirculation of the liquid phase and guarantees that a saturated vapor leaves the evaporator towards the compressor.

Test $c$ was carried out to compare circuitry layouts of Set 1 with those of Set 2. Both sets have the same refrigerant path, with the same number of circuits, with the difference that in Set 1 the air inlet is placed on the same side of the refrigerant inlets, while in Set 2 air enters on the side where the refrigerant outlets are located. R32 was used in Test $c$ as working fluid with inlet conditions shown in Table 4. Results in Fig. 9 shows how also for circuitry configurations Set 2 the heat transfer rate decreases linearly as the number of circuits increases (a). However, by comparing Set 1 with Set 2 it is clear that the air inlet side does not significantly affect the performance of the HX in terms of heat transfer rate (Fig. 9 (a)). In any case, Set 2 has worse performance than Set 1 with an average deviation of $0.74 \%$ less, against a reduction in refrigerant pressure drops of $6.78 \%$ compared to those of Set 1 . Finally, the same parabolic trend of Test $a$ and Test $b$ is confirmed for refrigerant pressure drops: as the number of circuits increases, the pressure drops strongly reduce (Fig. 9 (b)). Test $d$ was run using R32 on the three configurations of Set 3 in order to study the impact of refrigerant path on the coil performance, keeping constant the number of circuits. For this 
reason, the HX used in Set 3 has a greater number of tubes per row than that in Set 1 and Set 2 .

Fig. 10 shows no significant influence of refrigerant path on heat transfer rate has been found for the studied cases a), b) and c) of Set 3. Heat transfer rate shows indeed a maximum deviation of $-0.03 \%$ of configuration b) with respect to a). A slightly larger difference, but always small in absolute terms, can be noticed if a comparison in terms of refrigerant pressure drops is made: the best layout is c) with a $0.4 \%$ lower pressure drops compared to configuration a).

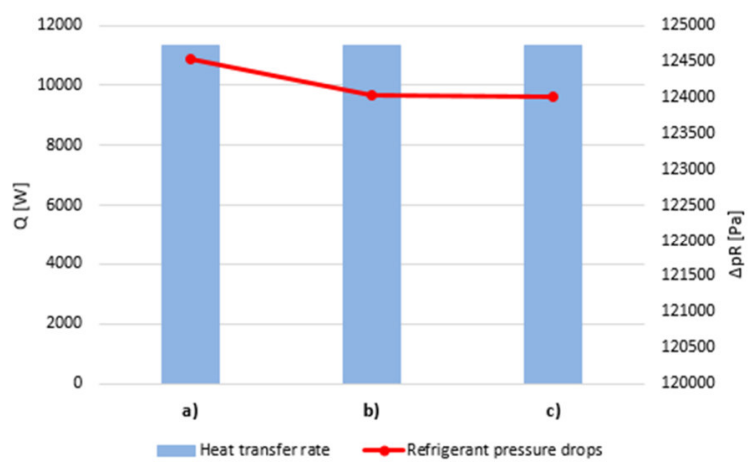

Fig. 10: Test $d$ : heat transfer rate and refrigerant pressure drops for circuitry configuration a), b) and c) of Set 3 .

\subsection{Performance Evaluation Criteria}

Main performance changes affected by heat exchanger design choices come from the following variations [16]:

- $\quad$ heat transfer surface area;

- air flow rate to the evaporator at fixed condenser and evaporator temperature difference;

- refrigerant flow rate at fixed evaporator heat duty.

Compressor power is affected by pressure drop in the whole circuit of a refrigeration unit as well as by the LMTD change caused by the saturation pressure decrease in both the evaporator and the condenser. Thus, the choice for the heat exchanger is a key factor to the whole unit design, while satisfying the imposed constraints.

Extrapolating data from the test results discussed in section 4, diagrams in Fig. 11 and Fig. 12 show the trade-off between $U A$ and $\Delta p_{R}$ for different refrigerants and per number of circuits,. All tests were performed at the same coil geometry and either air or refrigerant inlet conditions but different refrigerant paths. Each point on the diagram corresponds to a single tested circuitry layout (set 1, Fig. 3). It must be here underlined that, as demonstrated with Test $d$ and as discussed in section 4, even if an optimization of the refrigerant path with the same number of circuits is possible, the expected variations in terms of $U A$ and pressure drop would be very small. As a consequence, the values in Fig. 11 and Fig. 12 can be assumed representative of the real evaporator performance referred to a given number of circuits.

All refrigerants show the same trend but with different curve slope due to specific properties of each refrigerant: the 8-circuit configuration produces a small reduction in $U A$ but also a strong decrease in its pressure drop, if compared to 2-circuit layout.

Considering all the refrigerants and comparing the 8-circuits configuration with the 2circuits one the pressure drop variation range goes from $87.63 \%$ to $88.05 \%$, with minimum and maximum variations in $U A$ respectively of $11.36 \%$ and of $23.69 \%$. From this point of 
view, R32 shows the best behaviour among the tested refrigerants . Switching from a 2circuits configuration to a 8-circuits one, with a small reduction in $U A$ of $11.36 \%$, with R32 it is actually possible to obtain a decrease of the pressure drop of $87.63 \%$. On the other hand, working with R1234ze, by choosing an 8-circuits configuration instead of a 2-circuits on an evaporator, achieving a reduction in pressure drop of $87.89 \%$ costs a more significant deterioration of $U A$ equal to $23.69 \%$.

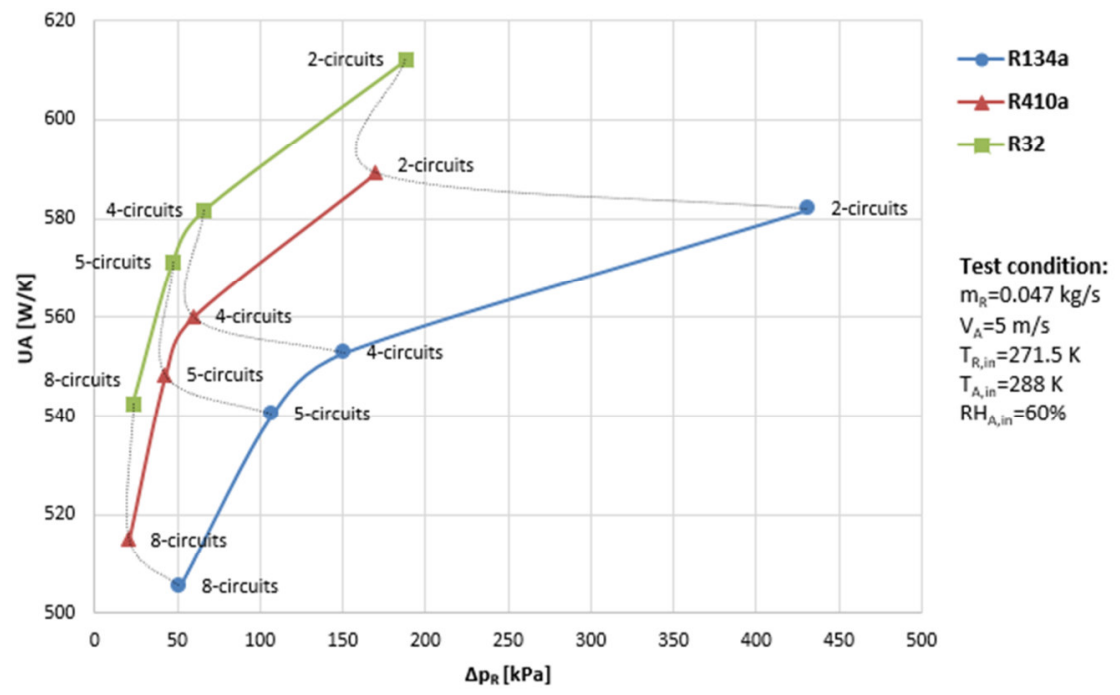

Fig. 11: $U A$ vs refrigerant pressure drop diagram for refrigerants R134a, R410a and R32 showing the effect of the number of circuits choice.

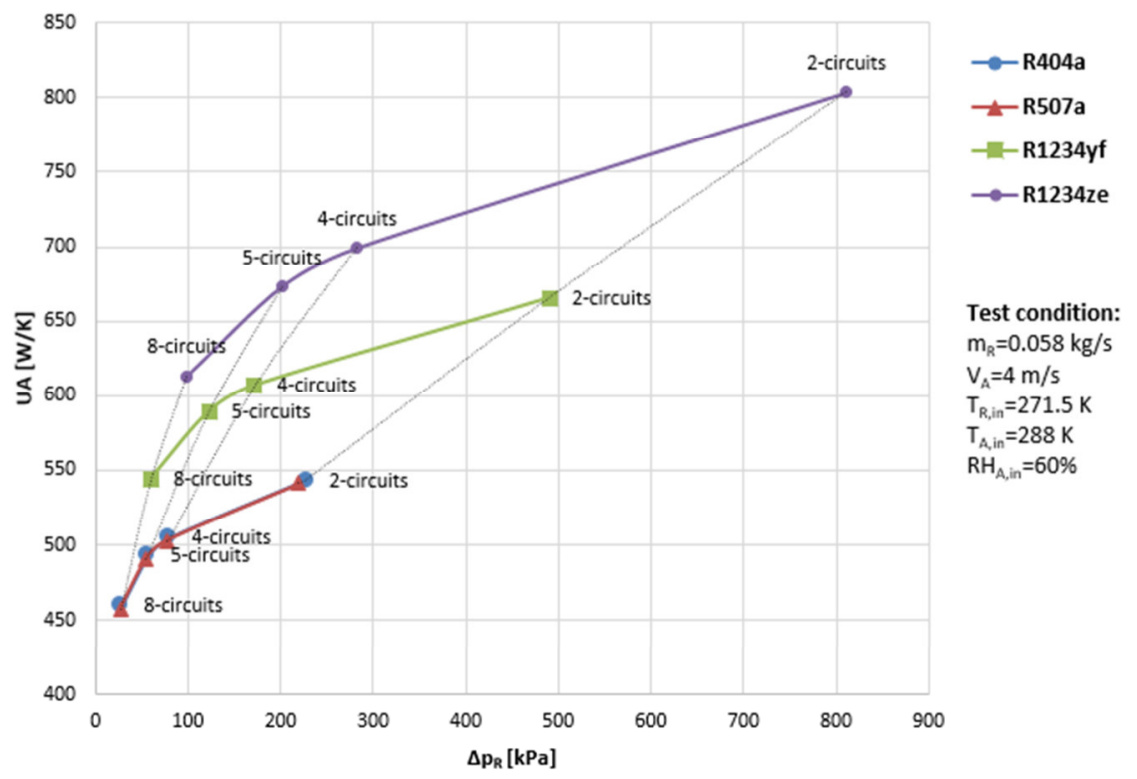

Fig. 12: $U A$ vs refrigerant pressure drop diagram for refrigerants R404a, R507a, R1234yf and R1234ze showing the effect of number of circuits choice. 


\section{Conclusions}

In this work, a new feature has been added to the hybrid method in order to make it adaptable to plate finned tube evaporators with complex circuit arrangements. The multiscale model which performs a local analysis to obtain the heat transfer properties on each elementary volume, was implemented to compare different circuitry layouts in order to give designers useful elements for the design process. Here, data from experimental correlations found in literature were used to find, through the regression technique, the prediction function, then used to compute refrigerant and air side thermodynamic properties. Four different tests were run on three sets of circuits. Results showed that heat transfer rate decreases almost linearly when the considered number of circuits increases, while refrigerant pressure drops strongly decrease with a parabolic trend due to flow rate reduction through each circuit, for all the tested refrigerants (R134a, R410a, R32, R404a, R507a, R1234yf, R1234ze). Other tests performed with R134a on different circuitry arrangements at same heat transfer rate showed that an 8-circuits configuration can be chosen to reduce refrigerant pressure drop of $45.3 \%$ and so operating costs, by increasing the refrigerant flow rate of $314 \%$ while maintaining the same performance in terms of heat transfer rate. Also, vapor quality decreases, with the possibility to recirculate the liquid phase through the evaporator, making sure that the fluid reaches the compressor as saturated vapor, as happens in flooded evaporators.

More investigations performed on other circuitry layouts showed that the air inlet side does not significantly influence the performance of the HX in terms of heat transfer rate. Anyway, configurations with air inlet placed on the opposite side with respect to the refrigerant entrees had worse performance than those on the same side with an average deviation of $0.74 \%$ less in heat transfer rate, against a reduction in refrigerant pressure drops of $6.78 \%$. In addition, other tests showed that a fine optimization of the refrigerant path at same number of circuits is possible, but the benefit in terms of increased performance is very small. Finally, by extracting the data from all the tests, trade-off curves showing $U A$ against refrigerant pressure drop were made for all the tested refrigerants and per number of circuits, in order to give designers a criterion to evaluate the performance of an evaporator when the circuitry configuration changes.

\section{Nomenclature}

$\begin{array}{ll}A & \text { heat exchange surface }\left(\mathrm{m}^{-2}\right) \\ G & \text { mass flux }\left(\mathrm{kg} \mathrm{m}^{-2} \mathrm{~s}^{-1}\right) \\ i & \text { enthalpy }\left(\mathrm{J} \mathrm{kg}^{-1}\right) \\ L M T D & \text { log-mean temperature difference }(\mathrm{K}) \\ m & \text { mass flow rate }\left(\mathrm{kg} \mathrm{s}^{-1}\right) \\ \Delta p & \text { pressure drop }(\mathrm{Pa}) \\ Q & \text { heat transfer rate }(\mathrm{W}) \\ R H & \text { relative humudity } \\ T & \text { temperature }(\mathrm{K}) \\ U & \text { overall heat transfer coefficient }\left(\mathrm{W} \mathrm{m}^{-2} \mathrm{~K}^{-1}\right) \\ V & \text { velocity }\left(\mathrm{m} \mathrm{s}^{-1}\right) \\ w & \text { air specific humidity }\left(\mathrm{kg}^{-1}\right) \\ x & \text { vapor quality }\end{array}$

\begin{tabular}{|c|c|}
\hline \multicolumn{2}{|c|}{ Greek symbols } \\
\hline$\beta$ & Regression coefficient \\
\hline \multicolumn{2}{|c|}{ Subscripts } \\
\hline$A, I$ & air, refrigerant \\
\hline$i$ & inner \\
\hline in & inlet \\
\hline$m$ & mean value \\
\hline$o$ & outer \\
\hline out & outlet \\
\hline$w$ & wall \\
\hline & viations \\
\hline$H X$ & heat exchanger \\
\hline
\end{tabular}

\section{References}

1. G. Starace, M. Fiorentino, M.P. Longo, E. Carluccio, A hybrid method for the cross flow compact heat exchangers design, Appl. Therm. Eng., 111, 1129-1142 (2017) 
2. E. Carluccio, G. Starace, A. Ficarella, D. Laforgia, Numerical analysis of a cross-flow compact heat exchanger for vehicle applications, Appl. Therm. Eng. E 25, 13, 19952013 (2005)

3. M. Fiorentino, G. Starace, The design of countercurrent evaporative condensers with the hybrid method, Appl. Therm. Eng., 130, 889-898 (2018)

4. G. Starace, M. Fiorentino, B. Meleleo, C. Risolo, The hybrid method applied to the plate-finned tube evaporator Geometry, Int. J. Refrigeration, 88, 67-77 (2018)

5. J.M. Corberan, P. Fernandez de Cordoba, S. Ortuno, V. Ferri, T. Setaro, G. Boccardi, Modelling of tube and fin coils working as evaporator or condenser, Proceedings of the 3rd European Thermal Sciences Conference, Heidelberg, Germany (2000)

6. A.H. Tarrad, A.K. Al-Nadawi, Modelling of finned-tube using pure and zeotropic blend refrigerants, ATINER'S Conference Paper Series TEN2015-1548, Athens, Greece (2015)

7. L. Tong, H. Li, L. Wang, X. Sun, Y. Xie, The effect of evaporator operating parameters on the flow patterns inside horizontal pipes, J. Therm. Sci. E 20, 4, 324$331(2011)$

8. C.M. Joppolo, L. Molinaroli, A. Pasini, Numerical analysis of the influence of circuit arrangement on a fin-and-tube condenser performance, Case Stud. Therm. Eng., 6, 136-146 (2015)

9. P.A. Domanski, D. Yashar, Optimization of finned-tube condensers using an intelligent system, Int. J. Refrigeration, 30, 482-488 (2007)

10. Z. Wu, G. Ding, K. Wang, M. Fukaya, Application of a genetic algorithm to optimize the refrigerant circuit of fin-and-tube heat exchangers for maximum heat transfer or shortest tube, Int. J. Therm. Sci., 47, 985-997 (2008)

11. H.Y. Ye, K.S. Lee, 2012. Refrigerant circuitry design of fin-and-tube condenser based on entropy generation minimization, Int. J. Refrigeration, 35, 1430-1438.

12. J.Y. Yun, K.S. Lee, Influence of design parameters on the heat transfer and flow friction characteristics of the heat exchanger with slit fins, Int. J. Heat Mass Transfer, 43, 2529-2539 (2000)

13. R.S. Matos, T.A. Laursen, J.V.C. Vargas, A. Bejan, 2004. Three-dimensional optimization of staggered finned circular and elliptic tubes in forced convection, Int. J. Thermal Sci., 43, 477-487 (2004)

14. M. Yilmaz, O. Comakli, S. Yapici, O.N. Sara, Performance evaluation criteria for heat exchangers based on first law analysis., J. Enhanc. Heat Transf. E 12, 2, 121-157 (2005)

15. M. Yilmaz, S. Karsli, O.N. Sara, Performance evaluation criteria for heat exchangers based on second law analysis, Exergy Int. J. E 1, 4, 278-294 (2001)

16. R.L. Webb, N.H. Kim, Principles of enhanced heat transfer (Taylor \& Francis Inc, 2005)

17. T.Y. Choi, Y.J. Kim, M.S. Kim, S.T. Ro, Evaporation heat transfer of R-32, R-134a, $R-32 / 134 a$ and $R-32 / 125 / 134 a$ inside a horizontal smooth tube, Int. J. Heat Mass Transf. E 43, 19, 3651-3660 (2000)

18. K. Stephan, M. Abdelsalam, Heat transfer correlations for natural convection boiling, Int. J. Heat Mass Transf. E 23, 1, 73-87 (1980)

19. B. Pierre, Flow resistance with boiling refrigerants - Part 1, ASHRAE J. E 6, 9, 5865 (1964) 
20. A. Bourabaa, M. Saighi, I. Belal, The influence of the inlet conditions on the air side heat transfer performance of plain finned evaporator, Int. J. Math. Comput. Phys. Elect. Comput. Eng. E 5, 11, 1667-1670 (2011)

21. C.C. Wang, Y.T. Lin, C.J. Lee, An airside correlation for plain fin-and-tube heat exchangers in wet conditions, Int. J. Heat Mass Transf. E 43, 10, 1869-1872 (2000)

22. K. Thulukkanam, Heat Exchanger Design Handbook, CRC Press (2013)

23. W.M. Kays, A.L. London, Compact Heat Exchanger, third ed. McGraw-Hill, New York (1984)

24. X. Ma, G. Dinga, Y. Zhanga, K. Wang, Airside heat transfer and friction characteristics for enhanced fin-and-tube heat exchanger with hydrophilic coating under wet conditions, Int. J. Refrigeration E 30, 7, 1153-1167 (2007)

25. S.Y. Liang, T.N. Wong, 2010. Experimental validation of model predictions on evaporator coils with an emphasis on fin efficiency, Int. J. Therm. Sci., 49, 187-195 (2010) 